\title{
BMJ Open Preventing avoidable hospital admissions after emergency care in humanitarian settings: a cross-sectional review of Médecins Sans Frontières emergency departments
}

\author{
Megan Naidoo (D) , ${ }^{1}$ James Lee, ${ }^{2}$ Miguel Trelles, ${ }^{2}$ Lee Wallis (D) ${ }^{3}$ \\ Kathryn M Chu (D) ${ }^{1}$
}

To cite: Naidoo M, Lee J, Trelles M, et al. Preventing avoidable hospital admissions after emergency care in humanitarian settings: a crosssectional review of Médecins Sans Frontières emergency departments. BMJ Open 2021;11:e049785. doi:10.1136/ bmjopen-2021-049785

- Prepublication history for this paper is available online. To view these files, please visit the journal online (http://dx.doi. org/10.1136/bmjopen-2021049785).

Received 04 February 2021 Accepted 18 June 2021

A) Check for updates

(c) Author(s) (or their employer(s)) 2021. Re-use permitted under CC BY-NC. No commercial re-use. See rights and permissions. Published by BMJ.

${ }^{1}$ Centre for Global Surgery, Department of Global Health, Stellenbosch University, Cape Town, South Africa

${ }^{2}$ Medical Department, Médecins Sans Frontières- Operational Centre Brussels, Brussels, Belgium

${ }^{3}$ Division of Emergency

Medicine, University of Cape

Town, Cape Town, South Africa

Correspondence to

Dr Lee Wallis;

lee.wallis@uct.ac.za

\section{ABSTRACT}

Objectives The aim of this study was to describe the types of emergency departments (EDs), and the acuity, types and disposition of conditions managed at Médecins Sans Frontières (MSF)-supported EDs in humanitarian settings.

\section{Design, setting, participants and outcome}

measures This was a multicentre, cross-sectional review of visits to MSF-supported EDs from 1 January 2014 to 31 December 2018. EDs were classified into advanced-level, general-level, paediatric and trauma. Variables analysed included: age group, condition, acuity and ED disposition. Frequencies and percentages stratified by ED type or region were reported.

Results MSF supported 26 EDs in 12 countries, with a total of 1388698 visits between 2014 and 2018. Most patients were discharged home ( $n=1097$ 456, 79\%), with nearly $0 \%$ mortality $(n=4692)$. The majority of visits at general-level and paediatric EDs were for medical conditions $(n=600088,78 \%$ and $n=45276,96 \%$, respectively), while nearly half of advanced-level EDs visits were for surgical conditions ( $n=201$ 189, 48\%). Almost all visits to trauma EDs were for surgical conditions $(\mathrm{n}=148078,98 \%)$. Overall, most surgical conditions were traumatic injuries $(n=484008,94 \%)$, the majority unintentional ( $n=425487,82 \%)$. The top three most common classified medical conditions were respiratory infections, malaria and diarrhoea.

Conclusions EDs are critical in improving the agility and access to emergency care (EC) in humanitarian settings. This study demonstrated that EC provision resulted in the majority of patients being discharged from EDs, helping prevent avoidable hospital admissions. These results could help better understand the healthcare needs of vulnerable populations, improve responsiveness to emergency conditions and support programmatic planning in humanitarian settings.

\section{INTRODUCTION}

In 2020, 1 in 45 people in the world needed humanitarian assistance; the highest in decades. ${ }^{1}$ Humanitarian crises span the
Strengths and limitations of this study

- Although the importance of emergency care is wellknown, there is a paucity of data describing the role of emergency departments in humanitarian settings where emergency care provision is crucial, given the severity and types of conditions encountered.

- This was a multicentre, cross-sectional review of robust and routinely collected data from Médecins Sans Frontières-supported emergency departments in 26 sites across 12 countries.

- While this study is limited by missing data as well as its retrospective, cross-sectional and descriptive nature, given the challenges of collecting data in a humanitarian setting, this study provides critical baseline data around emergency care provision that contribute to understanding the healthcare needs of vulnerable populations.

- These results describe the healthcare needs in humanitarian settings and can guide future programme planning.

globe. They can be acute or protracted, and often stem from war and conflict, natural disasters and epidemics. ${ }^{1}$ During a humanitarian crisis, the burden of disease in low- and middle-income countries (LMICs) is exacerbated, as under-resourced and fragile health systems are placed under additional pressure. ${ }^{2}$ Healthcare is provided by various sectors in LMICs, including non-governmental organisations (NGOs). NGOs provide adjunct support for vulnerable populations where public systems are unable to meet healthcare needs.

Médecins Sans Frontières (MSF, also known as Doctors Without Borders) is an independent medical humanitarian organisation. MSF aims to address gaps in the public sector and unmet need due to previous or ongoing humanitarian crises. The organisation 
provides medical and surgical care for a variety of emergency conditions, such as infectious diseases and traumatic injuries. Its humanitarian projects span over 70 countries, mostly in LMICs. MSF has expanded its role to support hospital and health system strengthening in select contexts to more sustainably address system-wide issues and healthcare gaps. ${ }^{34}$

Effective emergency care (EC) is critical to a comprehensive hospital system. EC aims to prevent death or disability due to injury or illness through the provision of urgent medical care, often in emergency departments (EDs). Importantly, EC requires timely recognition, triage, resuscitation and referral. ${ }^{5}$ Many conditions that contribute to death and disability in LMICs require EC. Emergency conditions contributed to over $50 \%$ of mortality in LMICs, with disabilityadjusted life years (DALYs) and years of life lost due to emergency conditions over 4 times higher in lowincome countries compared with high-income countries. ${ }^{6}$ Conditions that require EC include critical episodes of cardiovascular, respiratory and digestive/ enteric diseases, as well as injuries. ${ }^{6-8}$ Notably, the Disease Control Priorities in Developing Countries Project estimated a 54\% reduction in deaths in LMICs as a result of implementing EC systems. ${ }^{9}$ Moreover, the World Health Assembly formally recognised the need for EC and called for its member states to develop formal, integrated EC systems. ${ }^{10}$

EDs are a crucial primary or first point of contact for people with emergency health conditions and help prevent avoidable hospital admissions. They treat and mitigate a wide range of acute conditions, including traumatic injuries, obstetric emergencies, and communicable and non-communicable diseases (NCDs). ${ }^{11}$ Furthermore, EDs also increase access for patients who cannot receive long-term, continued care with a primary care provider, or need to seek care after-hours or on weekends, particularly in resource-constrained settings where outpatient clinics are limited. ${ }^{12}$ EDs provide hospital-based EC, public health surveillance and disaster response. ${ }^{13}$ Because of their critical role in an effective health system, MSF Operational CentreBrussels (OCB) has supported hospital EDs worldwide, particularly in the past decade. In 2018, MSF supported 19 EDs in 12 countries. ${ }^{4}$

Essential emergency and critical care is 'the care that all critically ill patients should receive in all hospitals in the world. ${ }^{14}$ It is important to understand the nuanced EC delivered in hospital EDs in a comprehensive, effective health system. Currently, there is a paucity of data describing the role of hospital EDs in EC provision in humanitarian settings. This gap is significant given the severity and types of conditions encountered in humanitarian settings. The primary aim of this study was to describe the types of EDs, and the acuity, conditions and ED disposition managed at MSF-supported EDs in humanitarian settings. These results could help better understand the healthcare needs of vulnerable populations, improve the agility and responsiveness to emergency conditions and support programmatic planning in humanitarian settings.

\section{METHODS}

\section{Study population and settings}

This was a multicentre and retrospective, cross-sectional review of routinely collected data from MSF-OCBsupported EDs. An MSF-supported ED was defined by the international MSF Emergency Medicine, Anaesthesia, Critical working group as a physical area within a medical facility that is specially staffed and equipped to provide emergency medicine services with a dedicated intake area for acutely ill and injured patients, and supported by MSF financial and human resources. The establishment of an ED in a humanitarian setting is based on MSF's mission to support people who are affected by conflict, epidemics, disasters or are excluded from the healthcare system. Humanitarian settings were defined based on the Sphere Standards as 'a range of situations including natural disasters, conflict, slow-onset and rapid-onset events, rural and urban environments, and complex political emergencies in all countries. ${ }^{15}$ As with other humanitarian reports, this study uses and expands on this definition to include countries within any phase of emergency or recovery context. ${ }^{16}$

ED doctors and nurses were hired according to local accreditation standards. As most had not done formal additional training in emergency medicine, MSF ED specialists did additional on-the-job training at all sites. Oversight in clinical care was provided by MSF field project management, coordination management, and the operational department and medical referents at the MSF headquarters.

MSF began robust and routine data collection from MSF-OCB-supported EDs in 2014. As a result, all documented visits to MSF-OCB-supported EDs between 1 January 2014 and 31 December 2018 in 26 sites in 12 countries were included (table 1). The World Bank classified the countries included in this study as low-income, with the exception of Mauritania and Pakistan, which were lower-middle-income countries, and Iraq, which was an upper-middle-income country. ${ }^{17}$

\section{Variables}

Variables analysed included: age group $(<5$ years $)$, condition, acuity and ED disposition. Acuity data were collected based on the South African Triage Scale (SATS) as this tool has been validated in resource-limited contexts. ${ }^{18}$ The standardised use of SATS allowed for the comparison of ED patient severity across MSF projects. Red (immediate/EC) and orange (very urgent) triage codes were classified as high acuity. Yellow (urgent) and green (routine) were designated as low acuity. ED disposition was categorised into discharged from the ED, admitted to inpatient care, referred to a higher level facility, died in 
Table 1 Total number of visits to Médecins Sans Frontières Operational Centre-Brussels-supported emergency departments, by emergency department type, 2014-2018

\begin{tabular}{|c|c|c|c|c|c|}
\hline & Advanced-level & General-level & Paediatric & Trauma & Total \\
\hline Afghanistan & & & & & $384096(28 \%)$ \\
\hline Chardara & & & & 9601 & \\
\hline Kabul & & 334249 & & & \\
\hline Kunduz & & & & 40246 & \\
\hline Burundi & & & & & $43806(3 \%)$ \\
\hline Bujumbura & & & & 43806 & \\
\hline Central African Republic & & & & & $119562(9 \%)$ \\
\hline Bangassou & & 87181 & & & \\
\hline Mpoko & & 32381 & & & \\
\hline Democratic Republic of Congo & & & & & $96125(7 \%)$ \\
\hline Baya & & & 1209 & & \\
\hline Bikenge & & & 11020 & & \\
\hline Bili & & & 19718 & & \\
\hline Masisi & & 50845 & & & \\
\hline Nyabiondo & & 13333 & & & \\
\hline Guinea & & & & & $10704(1 \%)$ \\
\hline Kouroussa & & & 10704 & & \\
\hline Haiti & & & & & 299207 (22\%) \\
\hline Martissant & 237318 & & & & \\
\hline Port-à-Piment & & 9069 & & & \\
\hline Tabarre & & & & 52820 & \\
\hline Iraq & & & & & $3899(0 \%)$ \\
\hline Hamam Al-Alil & & & & 3899 & \\
\hline Mauritania & & & & & $29255(2 \%)$ \\
\hline Bassikounou & & 29255 & & & \\
\hline Pakistan & & & & & $310050(22 \%)$ \\
\hline Bajaur & & 24383 & & & \\
\hline Karachi & & 100651 & & & \\
\hline Timergara & 185016 & & & & \\
\hline Sierra Leone & & & & & $4584(0 \%)$ \\
\hline Bo & & & 4584 & & \\
\hline South Sudan & & & & & $56877(4 \%)$ \\
\hline Bor & & 6090 & & & \\
\hline Doro & & 20716 & & & \\
\hline Gogrial & & 19973 & & & \\
\hline Pibor & & 10098 & & & \\
\hline Syria & & & & & $30533(2 \%)$ \\
\hline Idlib Governorate & & 30533 & & & \\
\hline Grand total & $422334(30 \%)$ & 768757 (55\%) & $47235(3 \%)$ & $150372(11 \%)$ & $1388698(100 \%)$ \\
\hline
\end{tabular}

Row percentages may not equal $100 \%$ due to rounding.

the ED and defaulted (absconded) before medical advice was given.

Conditions were classified as surgical and medical. Surgical conditions were conditions that required consultation by a surgeon. The classification of a surgical condition was done at the end of the ED visit. Surgical conditions included: intentional trauma, unintentional trauma, non-trauma and obstetric conditions. Medical 
conditions included: respiratory infections, malaria, diarrhoea, asthma and chronic obstructive pulmonary disease (COPD), cardiovascular disease, fever, poisoning, diabetes, psychosis, sexually transmitted infection, measles, epilepsy, cholera, meningitis, jaundice and sexual violence. Medical conditions that did not fall into one of the aforementioned categories were classified as 'other'.

EDs were classified into advanced-level, general-level, paediatric and trauma based on their primary focus. General-level EDs had the capacity to perform basic and essential EC in limited-care facilities such as primary health centres or small hospitals staffed by generalists (with or without full-time specialist doctors or surgeons). Advanced-level EDs were able to perform a higher level of EC (eg, fibrinolytic therapy to treat an ST segment elevation myocardial infarction) and advanced resuscitation measures (eg, endotracheal intubation or initiation of vasopressors). Advanced-level EDs were often staffed by international emergency medicine specialists. Both general-level and advanced-level EDs cared for patients of all ages and conditions. This is in comparison with paediatric and trauma EDs, which mostly focused on children ( $<18$ years old) and trauma cases, respectively.

\section{Data collection}

Data on all patients treated at MSF-supported EDs were recorded using data collection forms used for routine programmatic monitoring and evaluation. These data were recorded in patient registries, which were transcribed into an electronic database (Microsoft Excel) and centralised at the MSF-OCB headquarters in Brussels. All data were reviewed for completeness and accuracy. Data discrepancies were resolved with programme staff.

\section{Data analysis}

Data were analysed in Microsoft Excel 2016. Frequencies and percentages for age, acuity, ED disposition and condition, stratified by ED type or region, were reported.

\section{Patient and public involvement}

Patients or the public were not involved in the design, or conduct, or reporting, or dissemination plans of our research.

\section{RESULTS}

MSF-OCB-supported 26 EDs in 12 countries, with a total of 1388698 patient visits from 2014 to 2018. These visits took place in general-level $(\mathrm{n}=768757,55 \%)$, advanced-level $(\mathrm{n}=422334,30 \%)$, trauma $(\mathrm{n}=150372,11 \%)$ and paediatric EDs $(n=47235,3 \%)$. Seventy-six per cent $(n=36007)$ of visits to paediatric EDs were for children $<5$ years old. In contrast, only $9 \%$ ( $n=13277$ ) of visits to trauma EDs were children $<5$ years old (see tables 1 and 2).

The proportion of emergency surgical versus medical conditions varied by ED type. Across all EDs, there were $515757(37 \%)$ reported surgical conditions and 867836 $(62 \%)$ reported medical conditions. Five-thousand onehundred and five $(0.4 \%)$ visits were missing condition classification, with the majority from general-level EDs $(\mathrm{n}=4111,1 \%)$. Most visits at general-level and paediatric EDs were for medical conditions ( $\mathrm{n}=600088,78 \%$ and $\mathrm{n}=42276,96 \%$, respectively) while nearly half of

Table 2 Age, triage and disposition of visits to Médecins Sans Frontières Operational Centre-Brussels-supported emergency departments (EDs), by ED type, 2014-2018

\begin{tabular}{|c|c|c|c|c|c|}
\hline & Advanced-level & General-level & Paediatric & Trauma & Total \\
\hline Total visits & 422334 & 768757 & 47235 & 150372 & 1388698 \\
\hline \multicolumn{6}{|l|}{ Age } \\
\hline$<5$ years old & $83305(20 \%)$ & 275257 (36\%) & $36007(76 \%)$ & 13277 (9\%) & $407846(29 \%)$ \\
\hline$\geq 5$ years old & 339029 (80\%) & 487990 (63\%) & $11228(24 \%)$ & 137095 (91\%) & 975342 (70\%) \\
\hline Missing & $0(0 \%)$ & $5510(1 \%)$ & $0(0 \%)$ & $0(0 \%)$ & $5510(0 \%)$ \\
\hline \multicolumn{6}{|l|}{ Triage } \\
\hline High acuity & 234693 (56\%) & $186489(24 \%)$ & 7427 (16\%) & 36495 (24\%) & $465104(33 \%)$ \\
\hline Low acuity & $187297(44 \%)$ & $354453(46 \%)$ & 8446 (18\%) & $113840(76 \%)$ & $664036(48 \%)$ \\
\hline Missing & $344(0 \%)$ & $227815(30 \%)$ & $31362(66 \%)$ & $37(0 \%)$ & 259558 (19\%) \\
\hline \multicolumn{6}{|l|}{ ED disposition } \\
\hline Discharged & 322510 (76\%) & $634690(83 \%)$ & $24242(51 \%)$ & $116014(77 \%)$ & $1097456(79 \%)$ \\
\hline Admitted & $58783(14 \%)$ & 73548 (10\%) & $22488(48 \%)$ & 25218 (17\%) & $180037(13 \%)$ \\
\hline Referred & $28422(7 \%)$ & 20932 (3\%) & $344(1 \%)$ & $7254(5 \%)$ & $56952(4 \%)$ \\
\hline Died & 3795 (1\%) & $514(0 \%)$ & $143(0 \%)$ & $240(0 \%)$ & $4692(0 \%)$ \\
\hline Default & $5305(1 \%)$ & $7251(1 \%)$ & $18(0 \%)$ & $1578(1 \%)$ & $14152(1 \%)$ \\
\hline Missing & $3519(1 \%)$ & $31822(4 \%)$ & $0(0 \%)$ & $68(0 \%)$ & $35409(3 \%)$ \\
\hline
\end{tabular}

Column percentages may not equal $100 \%$ due to rounding. 


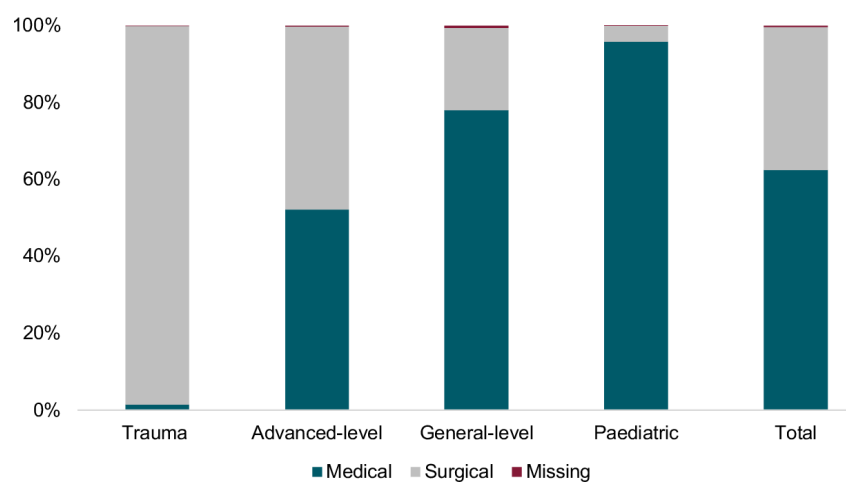

Figure 1 Visits to Médecins Sans Frontières Operational Centre-Brussels-supported emergency departments, by condition (\%) and emergency department type, 2014-2018.

advanced-level EDs visits were for surgical conditions $(\mathrm{n}=201189,48 \%)$. Almost all visits to trauma EDs were for surgical conditions $(n=148078,98 \%)$ (see figure 1). Among surgical conditions, most were traumatic injuries $(n=484008,94 \%)$, the majority unintentional $(n=425487$, $82 \%)$. The exceptions were paediatric EDs, where half of surgical visits were for non-trauma surgical conditions $(\mathrm{n}=1015,53 \%)$ (see table 3$)$.

The top 5 most common medical conditions were respiratory infections, malaria, diarrhoea, asthma or COPD, and cardiovascular conditions. Over one-third of medical conditions were unclassified and recorded as 'other,' $(n=311929,36 \%)$. Some medical conditions varied across ED types. Notably, 1 in 10 visits were for asthma or COPD $(n=23810,11 \%)$ and cardiovascular disease $(n=18336$, $8 \%)$ in advanced-level EDs, and diarrhoea $(n=75994$, $13 \%$ ) in general-level EDs. Malaria accounted for $60 \%$ of visits to the paediatric ED ( $\mathrm{n}=27191)$ (see table 4$)$.

Worldwide, the top 5 most common classified conditions were unintentional trauma, respiratory infections, malaria, diarrhoea and intentional trauma. Many conditions were common across regions, including non-classified 'other' medical conditions which were the second most common condition overall $(n=311929$, $23 \%$ ). However, the Caribbean had a different disease burden profile compared with other regions; asthma or COPD, fever and surgical non-traumatic conditions were common with unintentional trauma representing the majority of conditions in the region $(n=175719,59 \%)$ (see table 5).

There was a wide variation in high acuity visits between the different ED types. Overall, the proportion of high acuity cases was $33 \% \quad(n=465104)$. Over half of visits in advanced-level EDs were considered high acuity $(\mathrm{n}=234693,56 \%)$, whereas only a quarter were considered high acuity in general-level $(n=186489,24 \%)$ and trauma EDs $(n=36495,24 \%)$. Sixteen per cent of visits to the paediatric ED were high acuity cases $(n=7427)$ (see table 2).

Most patients were discharged home ( $n=1097456$, $79 \%)$. Thirteen per cent $(n=180037)$ were admitted, and $4 \%$ were referred $(n=56952)$. Only $1 \% \quad(n=14152)$ defaulted. Notably only half of patient visits to the paediatric ED were discharged $(n=24242,51 \%)$ with the other half hospitalised $(\mathrm{n}=22488,48 \%)$. Overall, mortality in the ED was very low $(n=4692,0.3 \%)$ (see table 2$)$.

\section{DISCUSSION}

EDs are a critical component of EC, particularly in humanitarian settings where populations are especially vulnerable to urgent medical conditions and surgical emergencies. In our study, there were over 1 million patient visits to MSF-OCB-supported EDs for a variety of emergency conditions, with the majority of patients discharged home and few patient deaths.

In MSF-OCB-supported EDs, medical conditions were more common than surgical ones. Common diseases reported in this study included respiratory infections, malaria, diarrhoea, asthma, COPD and cardiovascular conditions. These conditions greatly contribute to death and disability in LMICs. ${ }^{19}$ Notably, both communicable and NCDs were in the top 5 most common conditions reported by this study. This is reflective of the high burden LMICs, including those experiencing a humanitarian crisis, face. Many communicable and NCDs require urgent attention, and specifically EC through timely recognition, triage, and resuscitation and referral if necessary. Through their support of EDs and the hospital system, humanitarian medical organisations are helping address the double burden of communicable and NCDs.

Table 3 Visits for surgical conditions to Médecins Sans Frontières Operational Centre-Brussels-supported emergency departments, by emergency department type, 2014-2018

\begin{tabular}{llllll}
\hline & Advanced-level & General-level & Paediatric & Trauma & Total \\
\hline Total surgical conditions & 201189 & 164558 & 1932 & 148078 & 515757 \\
\hline Intentional trauma & $23545(12 \%)$ & $10493(6 \%)$ & $33(2 \%)$ & $24450(17 \%)$ & $58521(11 \%)$ \\
Unintentional trauma & $161599(80 \%)$ & $142219(86 \%)$ & $831(43 \%)$ & $120838(82 \%)$ & $425487(82 \%)$ \\
Non-trauma & $10973(5 \%)$ & $10707(7 \%)$ & $1015(53 \%)$ & $2733(2 \%)$ & $25428(5 \%)$ \\
Obstetric & $5072(3 \%)$ & $1139(1 \%)$ & $53(3 \%)$ & $57(0 \%)$ & $6321(1 \%)$ \\
\hline
\end{tabular}

Column percentages may not equal $100 \%$ due to rounding. 


\begin{tabular}{|c|c|c|c|c|c|}
\hline & Advanced-level & General-level & Paediatric & Trauma & Total \\
\hline Total medical conditions & 220281 & 600088 & 45276 & 2191 & 867836 \\
\hline Respiratory infection & $31280(14 \%)$ & $168090(28 \%)$ & $5434(12 \%)$ & $106(5 \%)$ & $204910(24 \%)$ \\
\hline Malaria & $10385(5 \%)$ & $85828(14 \%)$ & $27191(60 \%)$ & $27(1 \%)$ & $123431(14 \%)$ \\
\hline Diarrhoea & $11966(5 \%)$ & $75994(13 \%)$ & $2858(6 \%)$ & $111(5 \%)$ & $90929(10 \%)$ \\
\hline Asthma/COPD & $23810(11 \%)$ & $14503(2 \%)$ & $36(0 \%)$ & $16(1 \%)$ & $38365(4 \%)$ \\
\hline Cardiovascular & $18336(8 \%)$ & $16435(3 \%)$ & $3(0 \%)$ & $40(2 \%)$ & $34814(4 \%)$ \\
\hline Fever & $17176(8 \%)$ & $7452(1 \%)$ & $454(1 \%)$ & $123(6 \%)$ & $25205(3 \%)$ \\
\hline Poisoning & $4106(2 \%)$ & 3498 (1\%) & $83(0 \%)$ & $75(3 \%)$ & $7762(1 \%)$ \\
\hline Diabetes & $2871(1 \%)$ & $4152(1 \%)$ & $63(0 \%)$ & $5(0 \%)$ & $7091(1 \%)$ \\
\hline Psychosis & $4221(2 \%)$ & $1575(0 \%)$ & $13(0 \%)$ & $3(0 \%)$ & $5812(1 \%)$ \\
\hline Sexually transmitted infection & $67(0 \%)$ & $3976(1 \%)$ & $208(0 \%)$ & $8(0 \%)$ & $4259(0 \%)$ \\
\hline Measles & $1462(1 \%)$ & $2547(0 \%)$ & $202(0 \%)$ & $1(0 \%)$ & $4212(0 \%)$ \\
\hline Epilepsy & $1949(1 \%)$ & $2175(0 \%)$ & $21(0 \%)$ & $31(1 \%)$ & $4176(0 \%)$ \\
\hline Cholera & 167 (0\%) & $2174(0 \%)$ & $4(0 \%)$ & $6(0 \%)$ & $2351(0 \%)$ \\
\hline Meningitis & $637(0 \%)$ & $1157(0 \%)$ & 235 (1\%) & $1(0 \%)$ & $2030(0 \%)$ \\
\hline Jaundice & $120(0 \%)$ & $232(0 \%)$ & $1(0 \%)$ & $1(0 \%)$ & $354(0 \%)$ \\
\hline Sexual violence & $188(0 \%)$ & $13(0 \%)$ & $3(0 \%)$ & $2(0 \%)$ & $206(0 \%)$ \\
\hline Other & $91540(42 \%)$ & $210287(35 \%)$ & 8467 (19\%) & 1635 (75\%) & 311929 (36\%) \\
\hline
\end{tabular}

Column percentages may not equal $100 \%$ due to rounding.

COPD, chronic obstructive pulmonary disease.

Children who require EC also have specialised treatment needs. EDs tailored for children are crucial in their care. ${ }^{21}$ This study reported malaria as the most common medical condition in paediatric EDs. Seventy per cent of global malaria deaths occur among children under 5 years. ${ }^{22}$ Given children are one of the most vulnerable groups affected, MSF-OCB often establishes paediatric EDs in malaria-endemic regions. Supporting malaria prevention and treatment efforts must be a priority in a humanitarian setting. Furthermore, while the majority of adults were discharged after an ED visit, half of paediatric ED visits resulted in a hospital stay. This may have been influenced by the vulnerable nature of children and/ or sicker children required specialised care available at paediatric EDs. ${ }^{23}$ Dedicated paediatric EDs allow more timely access to specialised care in this vulnerable group.

Worldwide, one of the most common operations performed by MSF is a caesarean section, with over 27000 performed in 2019 alone. ${ }^{24}{ }^{25}$ In this study, the low rate of obstetric conditions presenting to EDs was likely due to direct referrals of pregnant women to the maternity ward, even in emergencies.

This study found that traumatic injuries were the main type of surgical condition and the majority of visits for trauma were unintentional. Trauma is common in LMICs, especially those experiencing a humanitarian crisis, and needs urgent attention. ${ }^{26}$ Nearly $90 \%$ of injury deaths occur in LMICs. Traumatic injuries account for 80 per
100000 deaths, with road accidents and falls ranking 10th and 16th overall causes of mortality in LMICs. ${ }^{19}$ For every death, there are hundreds of ED visits and non-fatal traumatic injuries can lead to disability and impact quality of life. Injuries accounted for 135 million DALYs in LMICs, with 99 million DALYs due to unintentional injury. ${ }^{20}$ Although effective prevention strategies are critical, EC for trauma is still needed. The systemic causes of injury often need to be addressed by the public (government) system, for example, lack of road safety regulations and enforcement. ${ }^{27}$ However, in the interim, non-government actors such as MSF are addressing urgent EC needs for trauma through their support of EDs. Notably, few children under 5 years old presented to trauma EDs. And while the vast majority of surgical conditions were traumatic injuries overall, less than half of surgical visits to paediatric EDs were for traumatic injuries. The reason for this needs further exploration.

The primary reason MSF-OCB supports EDs in humanitarian settings is to improve triage systems, patient flow and prioritisation of critically ill patients along the patient care continuum. ${ }^{4}$ As the first point of contact for patients with conditions that require urgent intervention, EDs allow timely triage and diagnosis of high acuity conditions which made up one-third of all visits. Importantly, the large majority of patients were discharged, helping prevent avoidable hospital admissions. 
In humanitarian settings, MSF-OCB helped hospital systems address urgent medical and surgical conditions where populations were particularly vulnerable. While this study did not evaluate the impact EC provision in MSF-OCB-supported EDs had on the overall health system, MSF has worked to expand its role in strengthening hospital and health systems in select settings. MSFOCB provided specialised EC based on the needs of the population (eg, establishing paediatric and trauma EDs, and cardiac care and HIV rapid assessment units within EDs). They have also supported local partnerships and clinical mentoring with Ministries of Health (MOHs), and aimed to increase capacity building through acute care short courses for field healthcare workers. Importantly, MSF-OCB has worked to integrate into the local health system by supporting local MOH EDs and hiring national staff. ${ }^{34}$ However, more research is needed to understand the role and impact of humanitarian medical organisations in strengthening local health systems. ${ }^{28}$

This study is limited by missing and unclassified data as well as its retrospective, cross-sectional and descriptive nature, possibly impacting the validity of the results. Undereporting and missing data can introduce bias and reduce the representativeness of the results. For example, over a third of medical conditions were not classified and nearly $20 \%$ of triage data were missing. As the data could not assume to be missing completely at random, patient-level data were not available and the focus of this study was on descriptive as opposed to inferential statistics, options to address the missing data through methods like case deletion and imputation were limited. However, given the challenges of collecting data in a humanitarian setting, this study provides critical baseline data around EC provision in EDs that contribute to understanding the healthcare needs of vulnerable populations.

In conclusion, EDs are critical in improving the agility and access to EC in humanitarian settings. This study has demonstrated that an NGO can support the provision of EC, serving over a million patient visits in 12 countries over a 4-year period. Visits for surgical versus medical conditions varied greatly by ED type, with unintentional trauma, respiratory infections and malaria the most common conditions requiring EC. These results describe the healthcare needs in humanitarian settings and can guide future programme planning.

Importantly, MSF-supported EDs allowed for early and definitive treatment of acute health conditions, allowing the majority of patients to be discharged and preventing avoidable hospital admissions with few patient deaths in humanitarian settings.

Contributors MN conceived the study, conducted the data analysis and data interpretation and drafted the manuscript. JL guided the design of the study and supported data acquisition and interpretation. MT conducted the data acquisition. LAW guided data interpretation. KC conceived the study, guided data interpretation and drafted the manuscript. All authors critically revised the manuscript content, approved the final version to be published and agree to be accountable for all aspects of the work in ensuring that questions related to the accuracy or integrity of any part of the work are appropriately investigated and resolved. 
Funding The authors have not declared a specific grant for this research from any funding agency in the public, commercial or not-for-profit sectors.

Competing interests None declared.

Patient and public involvement Patients and/or the public were not involved in the design, conduct, reporting or dissemination plans of this research.

Patient consent for publication Not required.

Ethics approval Ethical approval was given by the Médecins Sans Frontières Ethics Review Board, an independent ethics review board that screens research proposals by Médecins Sans Frontières. Individual patient consent was not separately obtained for the study or for patient information to be stored in the hospital database because this study was based on routinely collected data and all patient identifiers were removed prior to capture into the database and analysis.

Provenance and peer review Not commissioned; externally peer reviewed.

Data availability statement Data are available upon reasonable request. № additional unpublished data are available.

Open access This is an open access article distributed in accordance with the Creative Commons Attribution Non Commercial (CC BY-NC 4.0) license, which permits others to distribute, remix, adapt, build upon this work non-commercially, and license their derivative works on different terms, provided the original work is properly cited, appropriate credit is given, any changes made indicated, and the use is non-commercial. See: http://creativecommons.org/licenses/by-nc/4.0/.

\section{ORCID iDs}

Megan Naidoo http://orcid.org/0000-0003-2768-6228

Lee Wallis http://orcid.org/0000-0003-2711-3139

Kathryn M Chu http://orcid.org/0000-0002-8923-7447

\section{REFERENCES}

1 United Nations Office for the Coordination of Humanitarian Affairs. Global humanitarian overview 2020. Geneva, Switzerland: United Nations, 2019.

2 Aebischer Perone S, Martinez E, du Mortier S, et al. NonCommunicable diseases in humanitarian settings: ten essential questions. Confl Health 2017;11:17.

3 Médecins Sans Frontières. Where we work, 2020. Available: https:// www.msf.org/

4 Médecins Sans Frontières Medical Department Operational CentreBrussels. Emergency medicine. Geneva: Médecins sans Frontières, 2019.

5 Razzak JA, Kellermann AL. Emergency medical care in developing countries: is it worthwhile? Bull World Health Organ 2002;80:900-5.

6 Razzak J, Usmani MF, Bhutta ZA. Global, regional and national burden of emergency medical diseases using specific emergency disease indicators: analysis of the 2015 global burden of disease study. BMJ Glob Health 2019;4:e000733.

7 Gouda HN, Charlson F, Sorsdahl K, et al. Burden of noncommunicable diseases in sub-Saharan Africa, 1990-2017: results from the global burden of disease study 2017. Lancet Glob Health 2019;7:e1375-87.

8 GBD 2017 Causes of Death Collaborators. Global, regional, and national age-sex-specific mortality for 282 causes of death in 195 countries and territories, 1980-2017: a systematic analysis for the global burden of disease study 2017. Lancet 2018;392:1736-88.

9 Thind A, Hsia R, Mabweijano J. Prehospital and emergency care. In: Debas HT, Donkor P, Gawande A, et al, eds. Essential surgery: disease control priorities, third edition (volume 1). Washington, DC:
The International Bank for Reconstruction and Development / The World Bank, 2015.

10 The World Health Assembly. Resolution WHA 60.22: emergency-care systems. Geneva: World Health Organization, 2007.

11 Reynolds TA, Sawe H, Rubiano AM. Strengthening health systems to provide emergency care. In: Jamison DT, Gelband H, Horton S, et al, eds. Disease control priorities: improving health and reducing poverty. Washington, DC: The International Bank for Reconstruction and Development / The World Bank, 2017.

12 Morganti KG, Bauhoff S, Blanchard JC, et al. The evolving role of emergency departments in the United States. Rand Health $Q$ 2013;3:3.

13 Institute of Medicine. Hospital-Based emergency care: at the breaking point. Washington, DC: Institute of Medicine, 2007.

14 Schell CO, Gerdin Wärnberg M, Hvarfner A, et al. The global need for essential emergency and critical care. Crit Care 2018;22:284.

15 Sphere Association. The sphere Handbook: humanitarian charter and minimum standards in humanitarian response, 2018. Available: www. spherestandards.org/handbook

16 Landis D, Williamson K, Fry D, et al. Measuring violence against children in humanitarian settings: a scoping exercise of methods and tools. Child protection in Crisis Network and Save the Children UK, 2013. Available: http://www.cpcnetwork.org/wp-content/uploads/ 2014/06/Measuring-Violence-Against-Children-in-HumanitarianSettings-FINAL-REPORT.pdf

17 The World Bank. World bank country and lending groups Washington, DC, 2020. Available: https://datahelpdesk.worldbank. org/knowledgebase/articles/906519

18 Dalwai MK, Twomey M, Maikere J, et al. Reliability and accuracy of the South African triage scale when used by nurses in the emergency department of Timergara Hospital, Pakistan. S Afr Med J 2014;104:372-5.

19 World Health Organization. Global health estimates 2016: deaths by cause, age, sex, by country and by region, 2000-2016. Geneva: World Health Organization, 2018.

20 World Health Organization. Global health estimates 2016: disease burden by cause, age, sex, by country and by region, 2000-2016. Geneva: World Health Organization, 2018.

21 American Academy of Pediatrics Committee on Pediatric Emergency Medicine, American College of Emergency Physicians Pediatric Committee, Emergency Nurses Association Pediatric Committee. Joint policy statement--guidelines for care of children in the emergency department. Ann Emerg Med 2009;54:543-52.

22 World Health Organization. World malaria day 2017. Geneva: World Health Organization, 2017. Available: https://apps.who.int/iris/ bitstream/handle/10665/254993/WHO-HTM-GMP-2017.7-eng.pdf? sequence $=1$

23 Bourgeois FT, Shannon MW. Emergency care for children in pediatric and general emergency departments. Pediatr Emerg Care 2007;23:94-102.

24 Wong EG, Trelles M, Dominguez L, et al. Surgical skills needed for humanitarian missions in resource-limited settings: common operative procedures performed at Médecins sans Frontières facilities. Surgery 2014;156:642-9.

25 Médecins sans Frontières. Quick facts about surgery and trauma care. Available: https://www.msf.org/surgery-trauma-care

26 Reynolds TA, Stewart B, Drewett I, et al. The impact of trauma care systems in low- and middle-income countries. Annu Rev Public Health 2017;38:507-32.

27 World Health Organization. Preventing injuries and violence: a guide for Ministries of health. Geneva: World Health Organization, 2007.

28 Naidoo M, Naidu P, Shrime MG, et al. Humanitarian surgical care delivery: lessons for global surgical systems strengthening. J Public Health Emerg 2020;4:22. 